\title{
The activity domain as the nexus of the organization
}

\author{
Lars Taxén
}

\section{Linköping University Post Print}

\section{Tweet}

N.B.: When citing this work, cite the original article.

Original Publication:

Lars Taxén, The activity domain as the nexus of the organization, 2011, International Journal of Organisational Design and Engineering, (1), 3, 247-272.

http://dx.doi.org/10.1504/IJODE.2011.041164

Copyright: Inderscience

http://www.inderscience.com/

Postprint available at: Linköping University Electronic Press

http://urn.kb.se/resolve?urn=urn:nbn:se:liu:diva-111335 


\title{
The Activity Domain as the Nexus of the Organization
}

Lars Taxén

Linköping University

\begin{abstract}
The development, acquisition, adaptation, and diffusion of Enterprise Systems in organizations pose immense challenges. These challenges need to be addressed by considering the ES in a wider context, where aspects of individual knowledge, sense-making, technology, and organizing are taking into account. In this contribution, the Activity Domain Theory is suggested as a unifying framework for these areas in one respect - the coordination of actions. The central constructs in this theory are the activity domain, which frames a social unit providing some capability that the organization needs; and the activity modalities, which represent innate predispositions for coordinating actions. Empirical results from the telecom industry are used to validate the approach in the areas of Organizational Design, Information Systems, and System Engineering.
\end{abstract}

\section{INTRODUCTION}

It is by now well accepted that fundamental issues related to Enterprise Systems (ES) such as Enterprise Resource Planning (ERP) systems, can only be solved by considering the ES in a wider context, which brings individual knowledge, sense-making, technology, and organizing into a coherent whole. Separate areas of investigations like organizational science, information systems, human-computer interaction, cognitive science and design science need to be brought closer together since there are obvious dependencies between them. In order to do so, it is necessary to find some common ground for investigations that spans across all these separate areas, and yet is powerful enough to provide interesting and useful results. I propose that one such foothold is the coordination of actions.

Coordination is at the heart of human reality; by necessity we need to coordinate our actions, both when acting alone and together with other people. Grant claims that the "fundamental task of the organization is to coordinate the efforts of many specialists. Although widely addressed, organization theory lacks a rigorous integrated, well developed and widely agreed theory of coordination." (Grant, 1996, p. 113). Concerning ERP systems, Kumar \& Van Hillegersberg state that "The problem of coordination is counted as one of the most important issues leading to failure of a number of ERP implementations" (Kim, Lee, \& Gosain, 2005, p. 159). Nicolini identifies a lack of knowledge about how coordination is actually carried out in practice:

In spite of the recent resurgence of interest in the study of coordination (Bechky 2003, 2006), we still know markedly little about the practice of coordination and, above all, the coordination of practices and knowings. (Nicolini, 2010, p. 16)

The purpose of this contribution is to put forward the Activity Domain Theory (ADT; Taxén, 2009) as a unifying framework for the coordination of actions. In order to ground the discussion in well-researched areas, I will use the hitherto loosely connected disciplines of Organizational Design (OD), System Engineering (SE) and Information Systems (IS) (see Figure 1): 


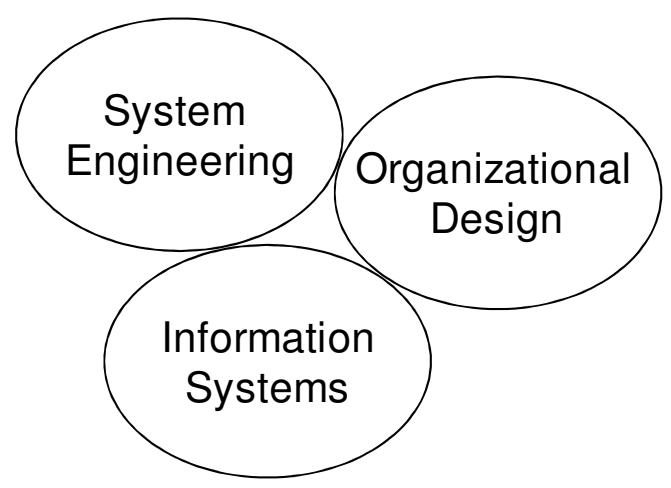

Figure 1: Three related areas of inquiry

OD is concerned with the alignment of structure, process, knowledge, IT support, etc., with the strategy of the business. Studies in this area are mainly analytical in nature, meaning that organizational phenomena are first and foremost explained (Earl, 1996). A deep engagement with technology is rare (Orlikowski \& Scott, 2008). Operative approaches, tools, and methods for intervening in organizations emanate by and large from the organizational practice itself, as exemplified by the emergence of Business Process Reengineering (Al-Mashari \& Zairi, 1999), ERP systems (Akkermans, \& van Helden 2002), and Service Oriented Architectures (Arsanjani et. al, 2007) in organizations.

The SE area, on the other hand, is positioned towards the technological other end of the spectrum. It is an interdisciplinary field of engineering, focusing on how complex engineering projects should be designed and managed over the life cycle of the project. Thus, SE is an industry-oriented discipline focusing on "getting things done" with little interest for the theoretical intricacies (Wikipedia, 2010).

The IS area takes on a middle position, in the sense that has outspoken agenda of providing relevant and useful information management systems to practitioners. However, the IS discipline has not been able to leverage its findings to influence largescale, organization-wide ES development in practical settings. A conspicuous example is that one particular type of ESs, the so called Product Lifecycle Management systems (PLM; Wikipedia, 2010b) is virtually non-existing in academia, although they represent the information backbone in product development companies. In fact, PLM systems are prerequisites for ERP systems, since PLM systems support the development of product / services that are subsequently managed in the ERP system.

\section{Some unresolved dilemmas}

In order to advance the analysis, at least the following major obstacles need to be overcome.

\section{Practical relevance}

The sociologist Kurt Lewin once said that "there is nothing so practical as a good theory". As a general motto, this view is no doubt acknowledged among practitioners and academics. In reality, it is far from being implemented:

The sad fact is that most Engineers actually writing code do not come to these conferences. They also do not read IEEE Transactions on Software Engineering. However, if we want to influence the way that software is written, we have to admit that we are doing something wrong. (Parnas, 
1995, p. 30)

This sad fact still remains even today:

[We] publish papers in our journals that, while they are of interest to the academic community, are of little interest to IS practitioners. As a result, practitioners are not attracted to our journals. Our journals often contain little that is relevant to practitioners' concerns, and they are busy people (McCubbrey, 2003, p. 553).

Practitioners feel that academic research is irrelevant since - so it is believed academia has no real understanding of the magnitude and complexity of practical challenges. Conversely, academics tend to regard the tinkering and ad-hoc solutions emanating from practice as less relevant vehicles for advancing theory development.

\section{Dualisms and dichotomies}

Dualism refers to the existence of two ontologically separate categories, such as the Cartesian dualism between mind and matter. According to Simpson, practice-oriented theories are "peppered with dualisms: theory vs practice, 'low' vs 'high' practices, rational action vs normatively oriented action, convergent vs divergent dynamics, individual vs social levels of analysis" (Simpson, 2009, p. 1332). This is in contrast to pragmatist and dialectical thinking, where two categories are dialectically related; meaning that opposites are different but mutually depending on and impacting each other within a totality (Israel, 1979). A non-problemized point of departure from a dualistic position is most likely futile since it will reinstate dispersed investigation areas.

Levels

A particularly problematic issue is the notion of 'levels' in organizational discourse. Sometimes this issue is referred to as the 'micro-macro' problem in social theory (see e.g. Wiley, 1988). 'Level' concerns what the proper unit of analysis should be in organizational inquires. Two common foci are the individual and the organization (see e.g. Lawrence \& Lorsch, 1967, p. 3). In between these levels a number of other analysis units can be found in the literature such as team, group, business unit, organizational networks, and more. Each level brings with it its own theoretical perspective, methods, body of knowledge, etc., which hinders a coherent knowledge accumulation and make it difficult to develop practical guidelines for intervening in organizations.

\section{Local and global}

Frequently, the notions of 'local' and 'global' are used without discrimination, as for example in the quotation below:

Just as the global can be explained as a nexus of locality, the local is itself fragmented and multiplied, a node in a complex nexus of actions that enter into it and that traverse it. Practice (including the practice of organizing) is the result of this complex interplay between local and global. (Nicolini, 2009, p. 1411)

As with the notion of levels, 'local' and 'global' need to be problemized and articulated in order to become practical vehicles for intervention. Local and global must be associated with some kind of reference - local and global in relation to what? Moreover, these notions need to be related to each other; when does the local become global and the other way around? 


\section{The way forward}

In order to confront the dilemmas above, as well as other issues, a growing number of scholars suggest departing from some kind of 'practice' construct (see e.g. Miettinen, Samra-Fredericks, \& Yanow, 2009). The aim is to ground theorizing in "what is actually done in the doing of work and how those doing it make sense of their practice" (Nicolini, 2009, p. 1391). In doing so, it is hoped to close "the chasm between practicedriven theorizing of what people do in their workplace and academic theory-driven theorizing about it" (Yanow 2006: 1745).

The ADT adheres to this line of thinking. It has two roots: a theoretical one in the Russian theory of Activity (Kaptelinin, \& Nardi, 2006) and practical one in the Ericsson $^{1}$ telecom practice, where the author worked for many years (Taxén, 2009). The central constructs in ADT are the activity domain and the activity modalities. The activity domain frames a social unit providing some capability that the organization needs. The activity modalities - contextualization, spatialization, temporalization, stabilization, and transition between contexts - represent innate predispositions for coordinating actions. They may be apprehended as an elaboration of Kant's a-priori categories of space and time by which we experience the world. The modalities of contextualization, stabilization, and transition provide additional a-priori categories by which we coordinate our actions in the world. As a consequence, mediational means enabling coordination in practice will reflect the activity modalities. Thus, the modalities provide a link between the individual and her social reality.

The paper is structured as follows. First, a brief account of the ADT is given. Next, the theory is used as a "“sensitising device" (Klein \& Myers, 1999) to analyse implications of ADT in the areas of OD, SE and IS. This is followed by a suggestion of how these areas can be related by aligning them around an axis of "dependencies between capabilities". Finally, the results are discussed and some conclusions drawn.

\section{THE ACTIVITY DOMAIN}

The notion of 'activity domain' is based on the central concept of 'activity' in Activity Theory (Kaptelinin \& Nardi, 2006). Activity was first introduced by Leont'ev as a fundamental unit in his investigations of the early manifestations of the mind in the human evolutionary history:

I will call the process of activity the specific processes through which a live, that is, active relation of the subject to reality is realized, as opposed to other types of processes. (Leont'ev, 1981, in Kaptelinin \& Nardi, 2006, p. 55)

A fundamental aspect of activities in this sense is that they cannot exist without objects: "Any activity of an organism is directed at a certain object; an 'objectless' activity is impossible" (ibid., p. 55). This is also the point of departure from which the idea of the activity domains emanates, as illustrated by the mammoth hunting scenario in Figure 2:

\footnotetext{
${ }^{1}$ Ericsson is a well-known leading supplier of telecommunication equipments worldwide: http://www.ericsson.com/ 


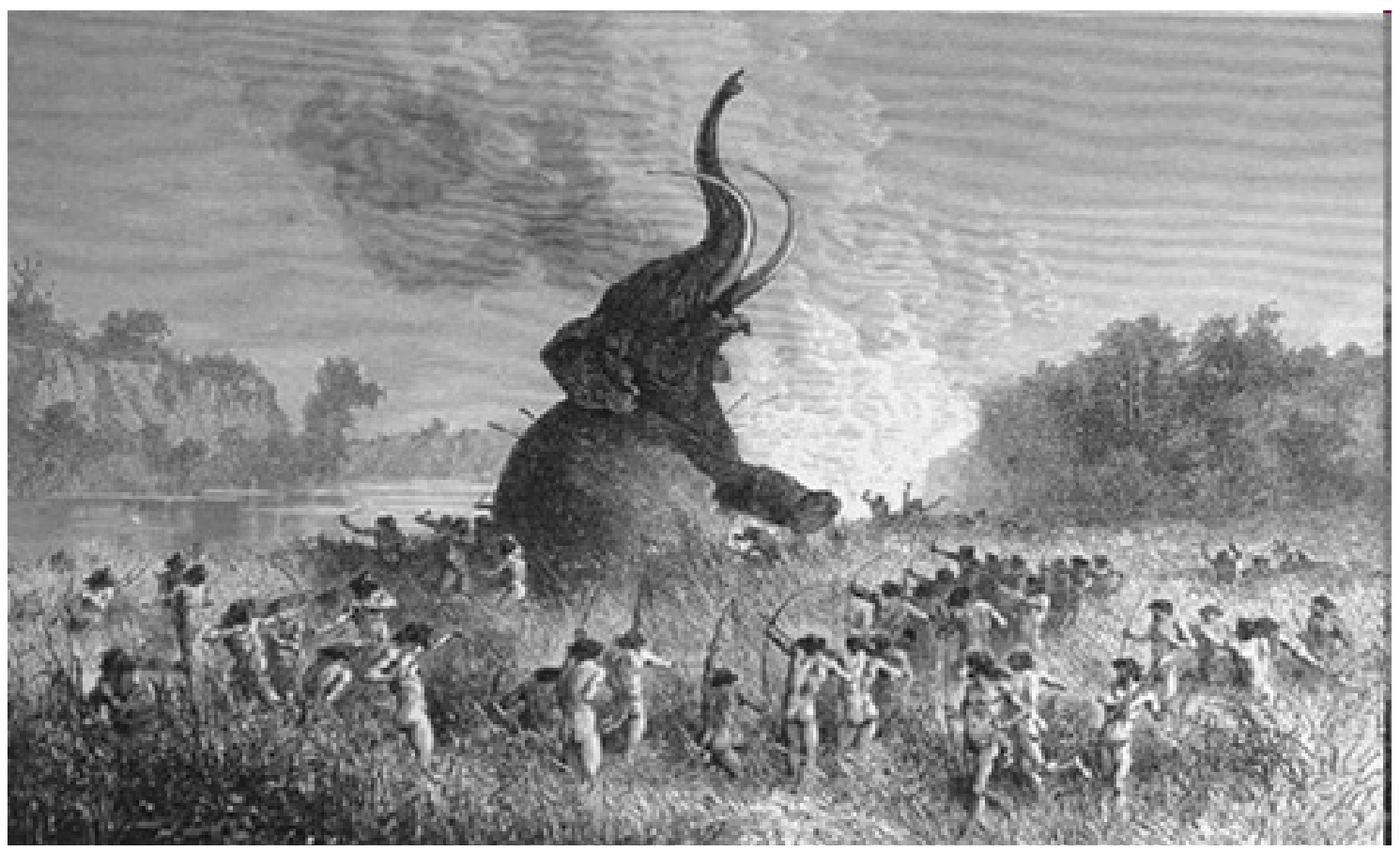

Figure 2: Illustration of an activity domain (Bryant \& Gay, 1883. Original wood engraving by E. Bayard).

When looking at this scene some things immediately come to mind. The mammoth is clearly the object in focus for actions. There are also several perceivable motives for the hunt, the primary one presumably being obtaining food. Related motives may be obtaining material for clothing, making arrowheads, and the like. Together, the object and the motive form a point of gravity around which everything else revolves: hunters, bows, arrows, actions, shouts, gestures, and so on.

Moreover, it is obvious that the hunters have to coordinate their actions; if every hunter attacked the mammoth one at a time, the result would be disastrous. In order to coordinate actions, certain capabilities are needed. To begin with, there must be a common understanding about the context surrounding the mammoth. This context frames the relevance of individual actions. For example, it can be seen in the background of the illustration that some hunters, the beaters, have started a fire and are making noise to scare the quarry away. The mammoth escapes in a direction where other hunters wait to circumvent the quarry and kill it. However, it is only in the context of the activity domain as a whole that the beaters' actions of scaring the quarry away make sense.

Second, a common sense of what is relevant in the context must be developed. This enables the actors to orient themselves in the same way that a map does. For example, the river in the background is probably relevant since it hinders the mammoth from escaping in that direction. On the other hand, the fishes in the river are certainly irrelevant in this activity, in contrast to, say, a fishing activity.

Third, individual actions must be carried out in a certain order. For example, the hunters must be in place before the beaters start making noise, the archers must shoot their arrows synchronously, and so on.

Fourth, the archers cannot shoot their arrows in any manner they like. If they shoot in 
the wrong direction, other hunters may be hit rather than the mammoth. Gradually, after many successful and less successful mammoth hunts, a common understanding about how to do appropriate mammoth hunting will evolve. This provides a common sense of the "taken for granted": rules and norms indicating proper patterns of action that need not be questioned as long as they work.

Fifth, activity domains are not isolated. The brought-down quarry will be cut into pieces and prepared for eating. This is done in a cooking activity, which in turn has its own particular motive (to still hunger) and object (which happens to be the same as that for the hunting activity: the mammoth). Other related activities might be manufacturing weapons and weapon parts from the bones and the tusks of the mammoth. When several domains interact, certain issues must be resolved in the transition between them, such as how to share the quarry among hunters and cooks, or how many ready-made arrowheads will be returned for a certain amount of food. Thus, there must be a common understanding about how different activity domains shall cooperate.

These five aspects - contextualization, spatialization, temporalization, stabilization, and transition between contexts - are called activity modalities in ADT. As a premise, they represent innate predispositions for acting in the world; predispositions that have emerged during the phylogenetic evolution of mankind. This means that the modalities are found in every human activity. The term 'activity modalities' is deliberately coined to connote with sensory modalities such as vision, hearing, touch, taste, smell, etc. Thus, the way we experience the world through our senses is transformed by our brains and bodies into a unified activity modality percept that enables coordination of actions (Taxén, n.d.).

A further aspect of the activity domain is that actions are always mediated by some means (Bødker \& Bøgh Andersen, 2005). The hunters make use of bows and arrows, the beaters use some kind of tools to make a fire, the assault on the mammoth is most certainly accompanied by gestures, commands, and so on. Each actor must, of course, learn how to use such means in order to become a resource in the mammoth hunting activity. This is a joint accomplishment of actor and means; so deeply intertwined that it is more appropriate to speak of "individual(s)-acting-with-mediational-means" rather than individual(s) alone when referring to the agent of action (Wertsch, 1991).

The result of this "enactment" process (Weick, 1988; Orlikowski, 2000) is actors capable of utilizing capabilities of means advantageously in some activity domain. When the actions of these actors are coordinated, the activity domain becomes a collective, social capability for producing a certain outcome. Thus, the concept of "capability" can be equally applied to individuals, means, and activity domains.

In summary, the activity domain may be characterized as follows:

- The activity domain is motivated by some need.

- This need is fulfilled by actions directed to an object.

- The object and motive impel the formation of a context in which actions make sense (contextualization).

- Actions require a spatial comprehension of the context (spatialization). 
- Actions are carried out in a certain order (temporalization)

- Actions require rules, norms, etc. that express which actions are valid in the domain (stabilization)

- Specialization of actions according to different motives and objects brings about a need to coordinate domains (transition)

- Enactment results in an idiosyncratic worldview, i.e., a domain specific way apprehending social reality.

- Coordinative capabilities are a combination of human capabilities and means capabilities.

- The activity domain represents a social capability which may use and be used by other domains.

\section{IMPLICATIONS}

In this section, I will discuss how the OD, SE, and IS investigation areas may be interpreted with the activity domain as a unifying construct.

\section{Organizational Design (OD)}

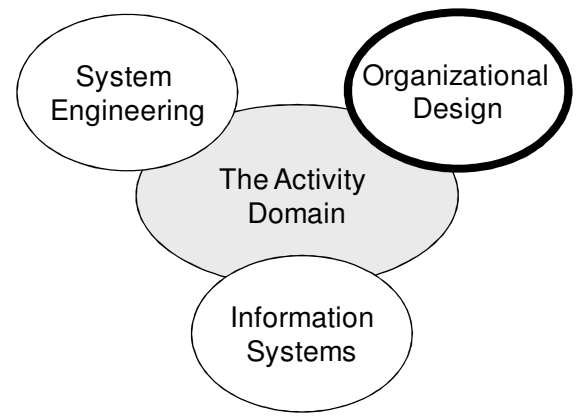

Figure 3: Focus on Organizational Design

A first observation concerning OD is that the reality in contemporary organizations is, in principle, not different from that facing the mammoth hunters in historical times. The fundamental structure of activities remains the same; only the objects - henceforth referred to as workobjects - motives, means, norms, etc., are different. This indicates that the activity domain should play an important role in OD.

In order to proceed, we need to articulate coordination from the ADT perspective. A starting point is to realize that there are two basic types of capabilities are needed in an activity domain: capabilities to perform transformative actions by which the workobject is transformed into an outcome, and capabilities to coordinate transformative actions:

Thus, by entering into cooperative work relations, the participants must engage in activities that are, in a sense, extraneous to the activities that contribute directly to fashioning the product or service and meeting requirements. That is, compared with individual work, cooperative work implies an overhead cost in terms of labor, resources, time, etc. (Schmidt, 1990, in Schmidt \& Bannon, 1992, p. 8)

In order to analytically distinguish between these types, the activity domain may be seen from two interrelated viewpoints: the transformative and the coordinative ones. These represent two different foci; one where the transformation of the workobject is in 
focus - the transformative mode - and one where coordination of transformative actions is in focus - the coordinative mode. These modes may be regarded as two intertwined activities where the transformative is the primary one, since this mode is directly related to the workobject. Consequently, coordination is seen as an activity in itself that has its own workobject - coordination.

The outcomes in the coordinative mode are artifacts like information models, process models, rules, information system (IS) support, etc.; means that are relevant for coordinating actions. Thus, the activity domain unfolds through an ongoing focal shift between the coordinative and transformative modes. This is illustrated in Figure 4:

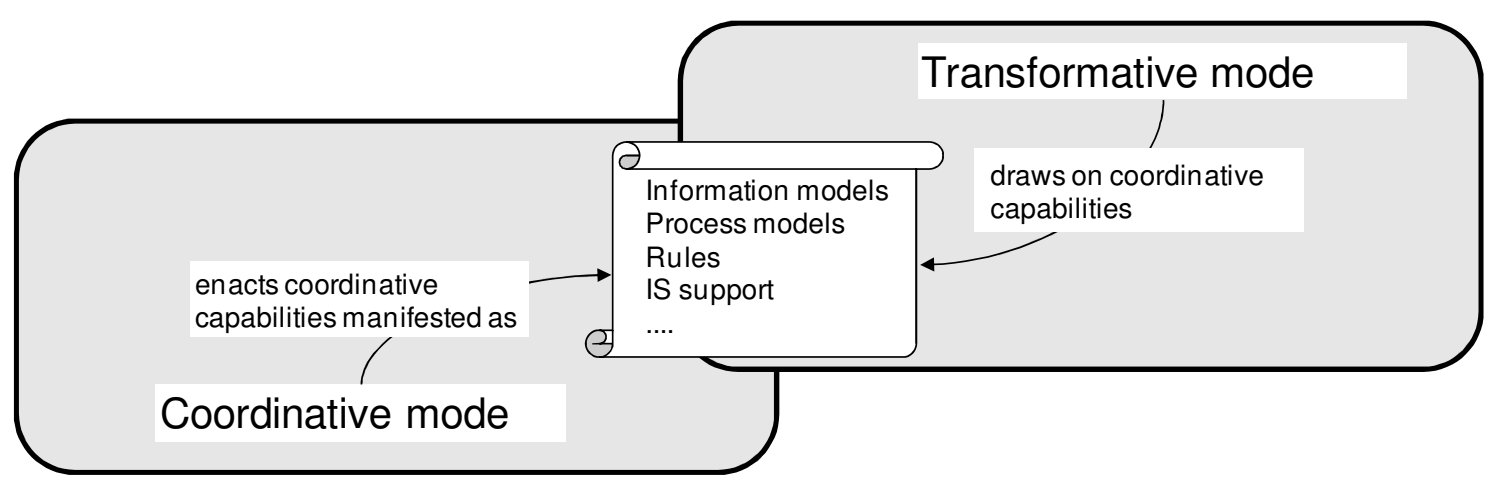

Figure 4: The two modes of the activity

This pattern of coordinative and transformative modes of actions can be generalized. When a certain activity domain employs other domains, these must be coordinated as well (see Figure 5):

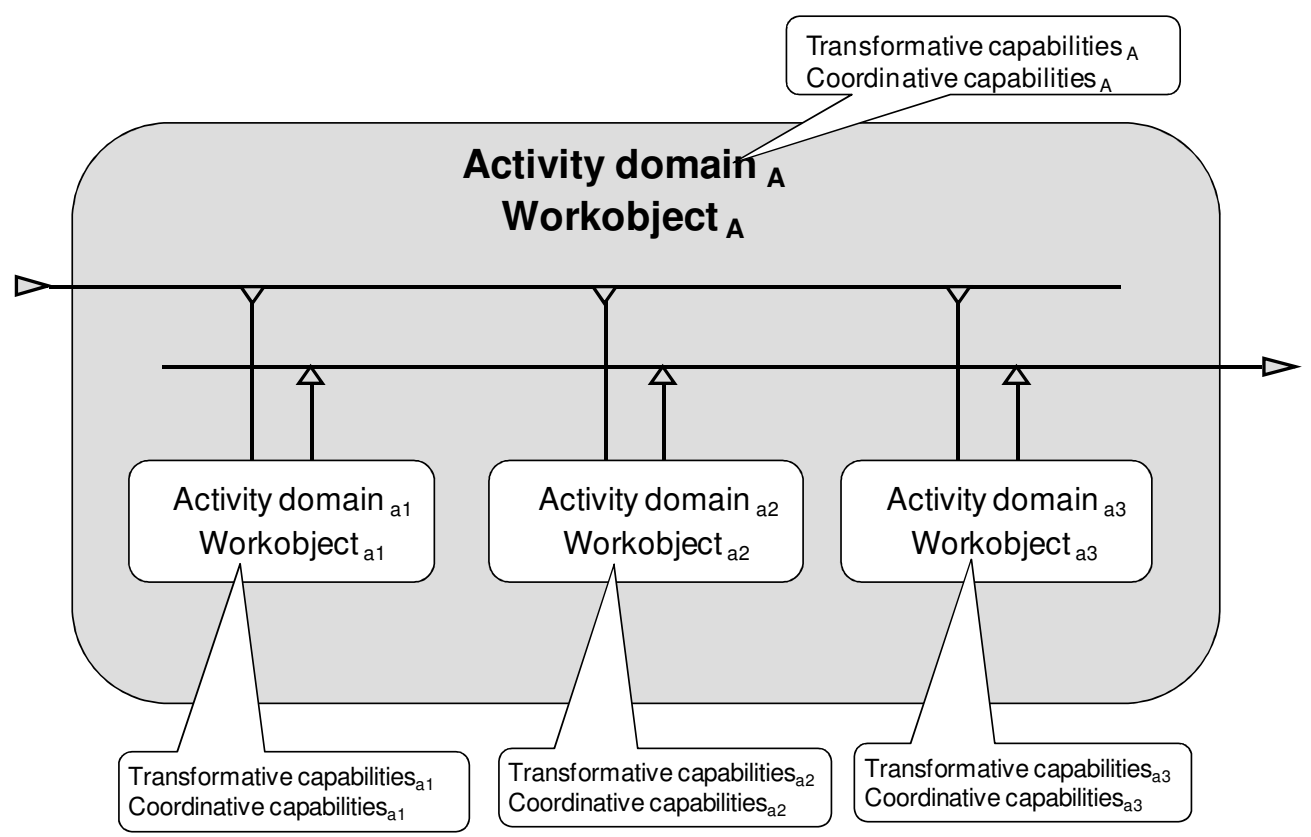

Figure 5: The recursive nature of the activity domain

Suppose a domain (A) utilizes three other domains a1, a2, and a3 in order to produce its outcome. The capabilities of these domain need to be coordinated by the A domain (symbolized in Figure 5 by the lines and arrows), which implies that domain specific coordinative capabilities must be developed in A. This pattern is repeated in each of a1, 
a2, and a3, which in turn may employ other domain, and so on. Thus, the organization can be apprehended as a confederation of activity domains; each of which enacts transformative and coordinative capabilities.

In the sections that follow we shall take a closer look at organizational manifestations of the activity modalities. The examples are mostly collected from the Ericsson development practice (Taxén, 2009).

\section{Contextualization}

Contextualization can be illustrated by the product development cycle in Figure 6:

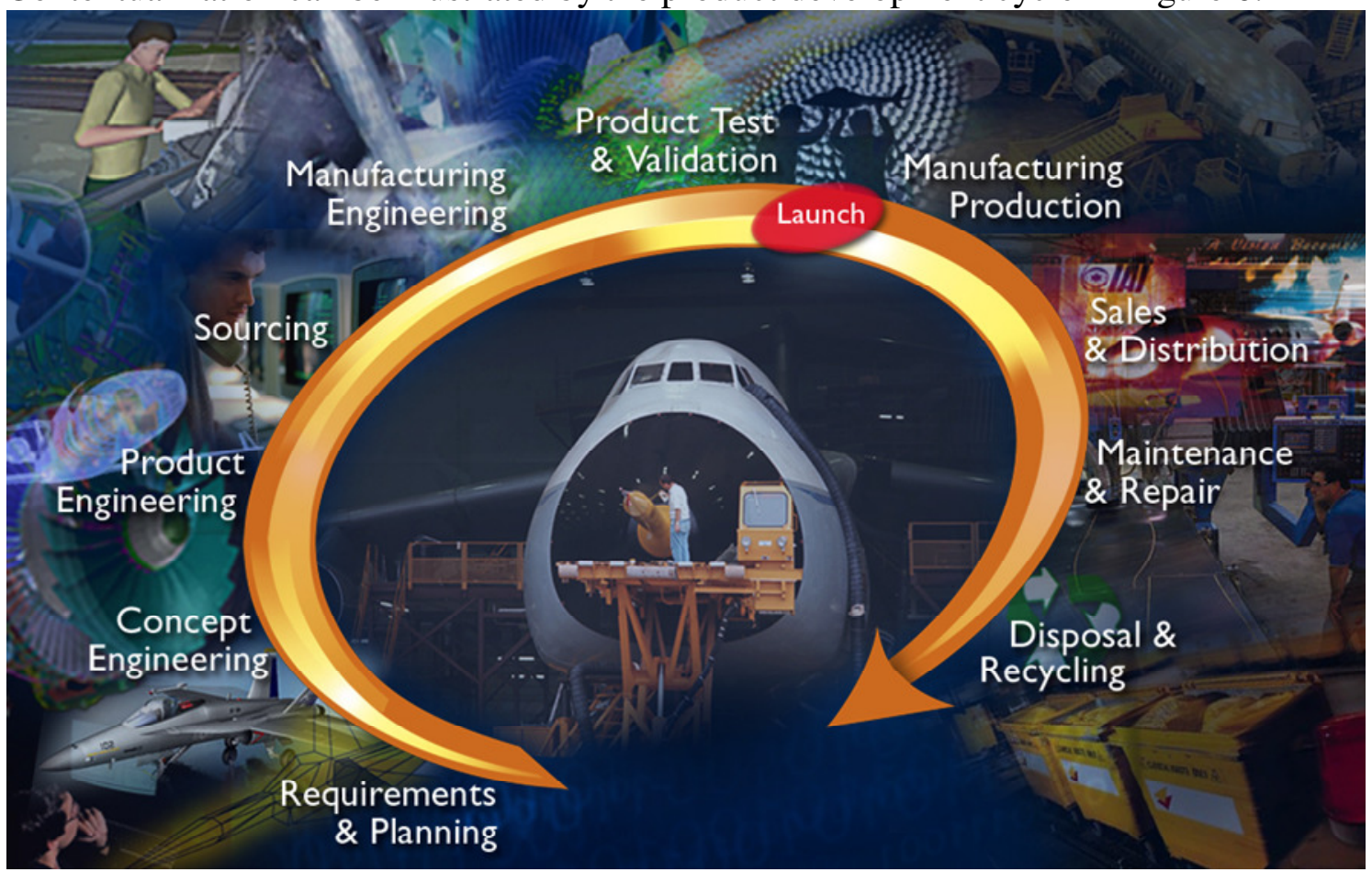

Figure 6: The lifecycle of a product (courtesy: Siemens PLM Software)

From its inception to its disposal, the product passes through a number of different activities such as marketing, design, manufacturing, distribution, maintenance, and finally, scrapping. These activities are examples of activity domains. Although the product is recognized as a particular individual throughout its lifecycle, it will be characterized differently in each of the contexts. When marketed, properties like appearance, price, availability, etc., are relevant. When manufactured, the manufacturability of the product is in focus. When disposed, recycling and environmental concerns are emphasized, and so on. In general, a product consists of many different parts that may be realized in various technologies like hardware, software, mechanics, optics, radio, etc. These parts are worked on in different activity domains with specific workobjects and motives.

\section{Transition}

Transition is, in short, the complement to contextualization. Since every domain evolves its own worldview there is a need to elaborate how the transition between the "inner" and "outer" of each activity domain shall be take place. For example, different terms and concepts used internally and externally must be reconciled in some way. The effort 
of developing these transitional capabilities is a substantial part of enacting coordination. An example of this from Ericsson is shown in Figure 7, which illustrates of how two activity domains - Research \& Development and Hardware Design - are coordinated in terms of rules mapping between information states. Such rules are examples of organizational transitional elements.

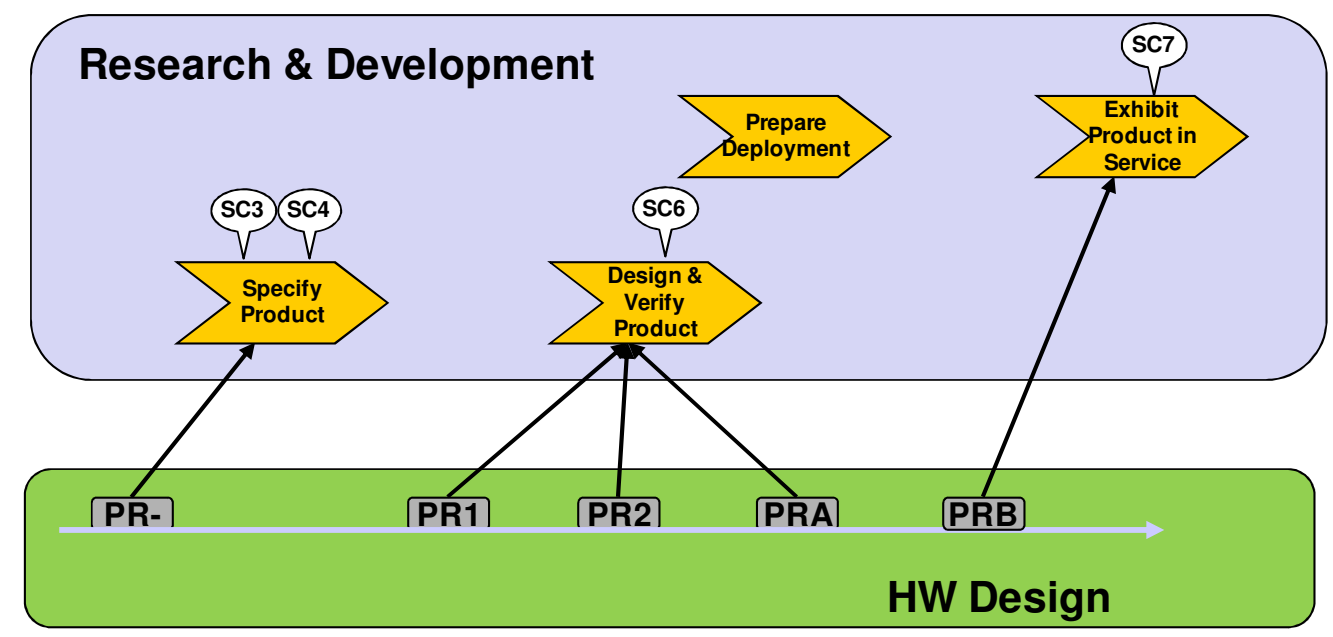

Figure 7: Mapping between states - a manifestation of transition

\section{Spatialization and temporalization}

Examples of spatial manifestations in organizations are information models (see Figure 8):

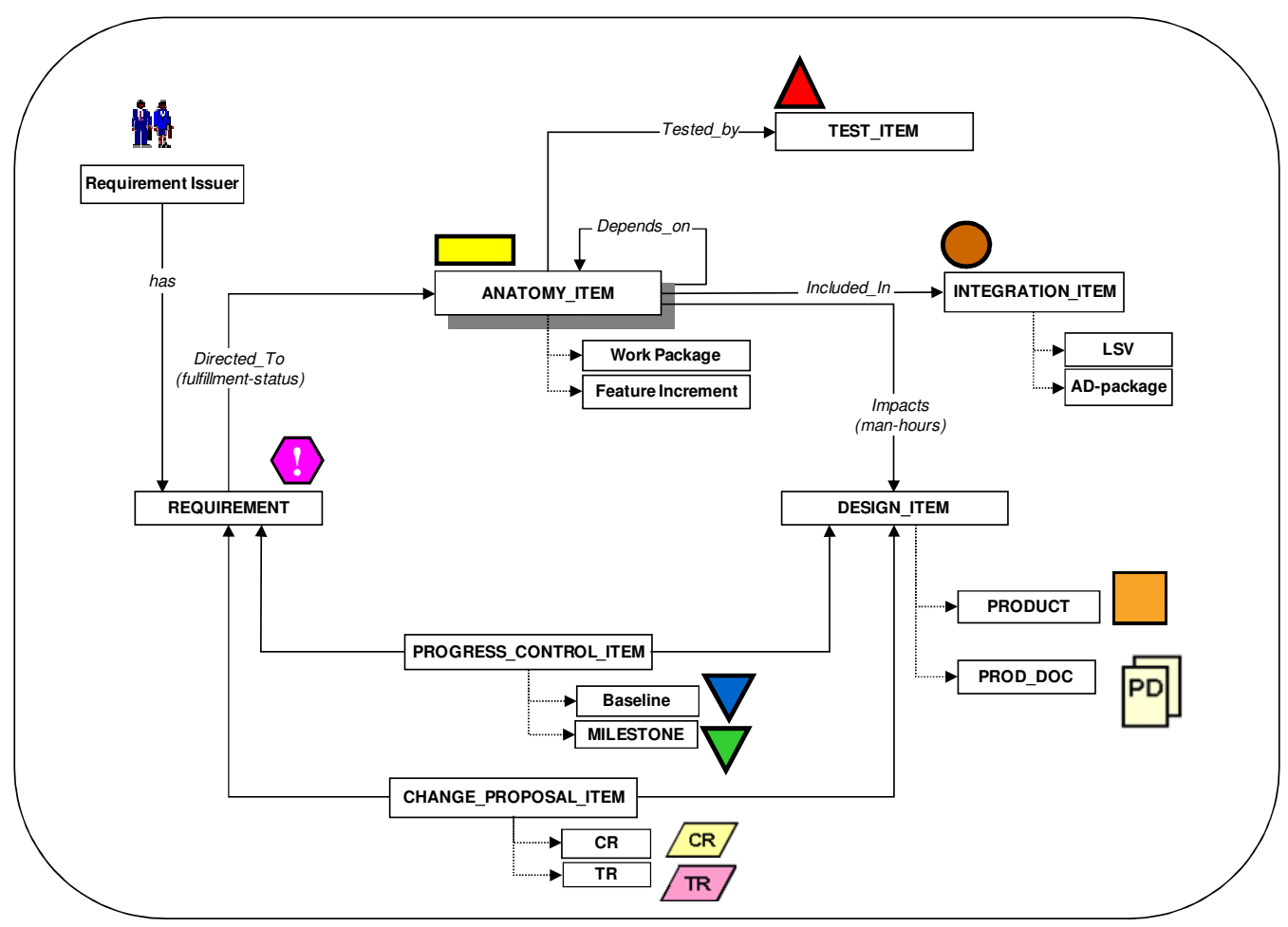

Figure 8: An information model - a manifestation of spatialization

The image shows an information model for coordinating the development of the $3^{\text {rd }}$ generation of mobile systems at Ericsson around year 2000. The model represents the common understanding of what actors in one particular domain considered relevant 
information elements for managing coordination. The enactment of this model, and its implementation in an information system, was a long and tedious process spanning several years (Taxén, 2009).

Business process models such as the one in Figure 9 are examples of manifestation of the temporalization modality:
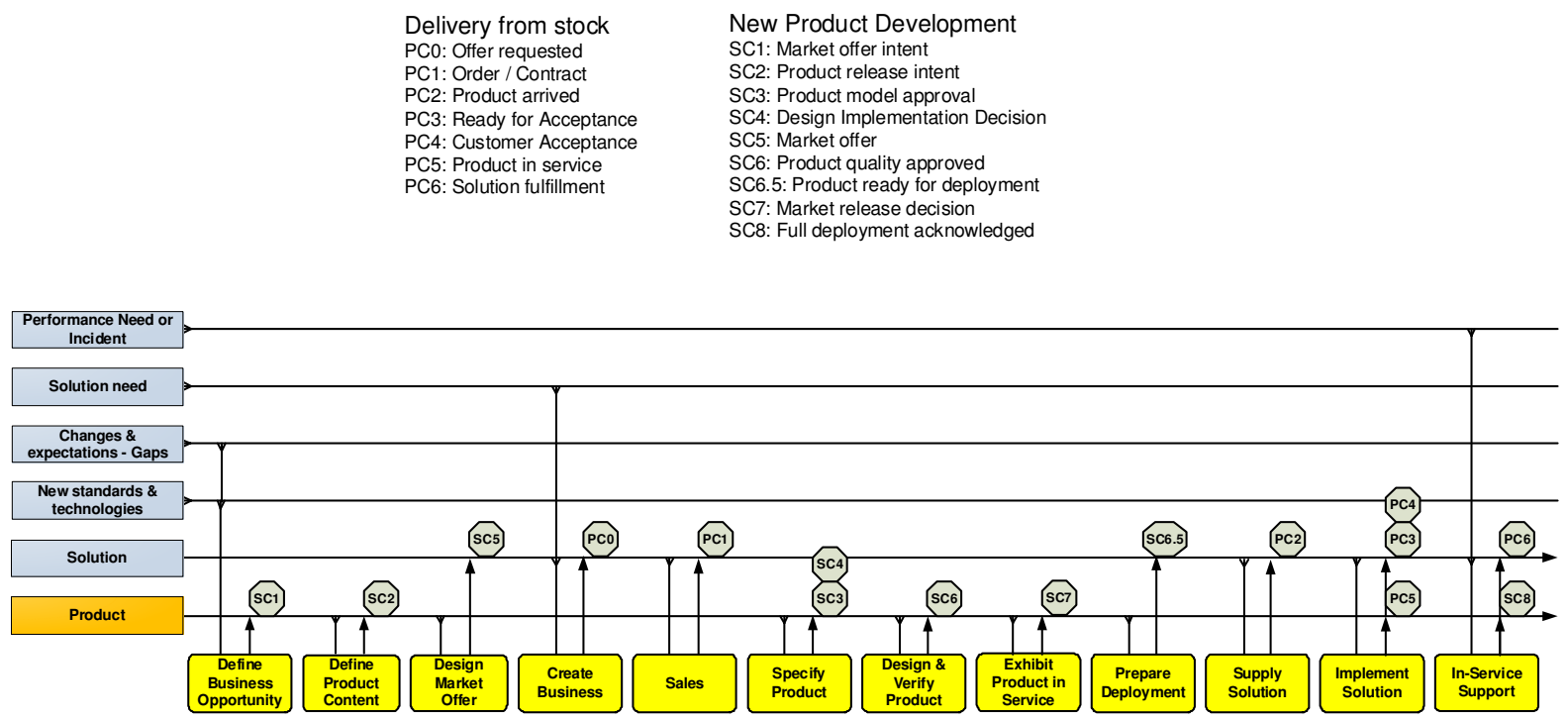

Figure 9: A business process model - a manifestation of temporalization (note that the entity 'Product' appears in both Figure 8 and Figure 9)

The important insight here is that the information model (spatialization) and the process model (temporalization) are two separate dimensions/modalities; yet tightly interrelated $^{2}$. For example, the information element "Product" appears in both modalities.

\section{Stabilization}

In a large and distributed organization like Ericsson, design centers around the world have certain autonomy to evolve locally in the manner they themselves find the best. At the same time, there must be some enterprise-wide common rules about how to approach customers, take heed for compulsory legislative norms, purchase materials, and so on. In Figure 10, an example of such a stabilizing element at Ericsson is shown; rules for how to identify products:

\footnotetext{
${ }^{2}$ In the vocabulary of the ADT, these dimensions/modalities are dialectically related; meaning that the modalities/parts constitute an inseparable whole, which in turn constitutes the modalities/parts (Taxén, 2009).
} 


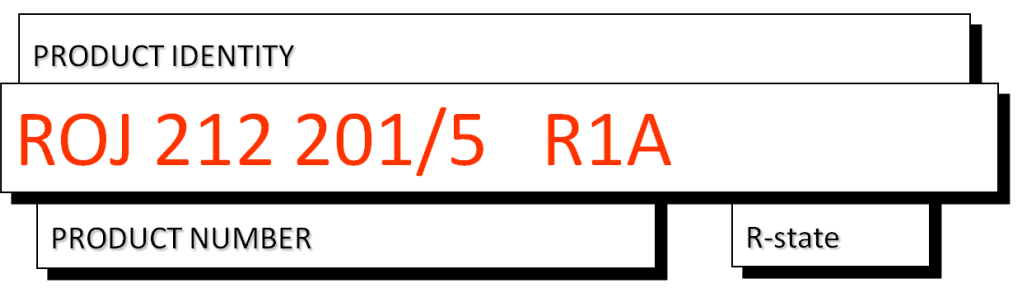

Figure 10: Rules for identification - a manifestation of stabilizing elements

As can be seen, the particular way such rules are manifested is idiosyncratic to the organization. For most people, they are completely unintelligible. In order to make sense of such rules, they need to be enacted in the Ericsson activity domain.

\section{System Engineering (SE)}

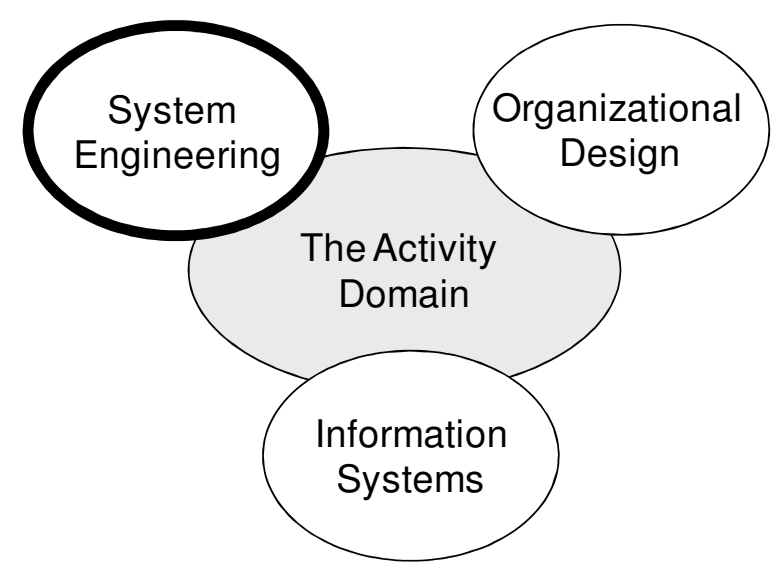

Figure 11: Focus on System Engineering

In order to discuss SE from the ADT perspective, we may to consider the development of telecom systems that are indeed extraordinary complex products. Such systems consist of many different parts in which various technologies are utilized: software, hardware, mechanics, fiber optics, and much more. Since the bulk of the functionality in telecom system is realized by software - which is not physically visible - a major issue is how to represent such systems in such a way that it is easily comprehended by humans, and still pertinent enough to support coordination efforts.

In the early 1990s, Ericsson devised a striking means of visualizing complex systems the system anatomy. The anatomy is an illustration - preferably on one page - that shows the dependencies between capabilities in the system from start-up to an operational system (Taxén, n.d.2). Here, capability shall be understood as the ability of a certain system element to provide something that other system elements need. An anatomy for a telecom processor is shown in Figure 12: 


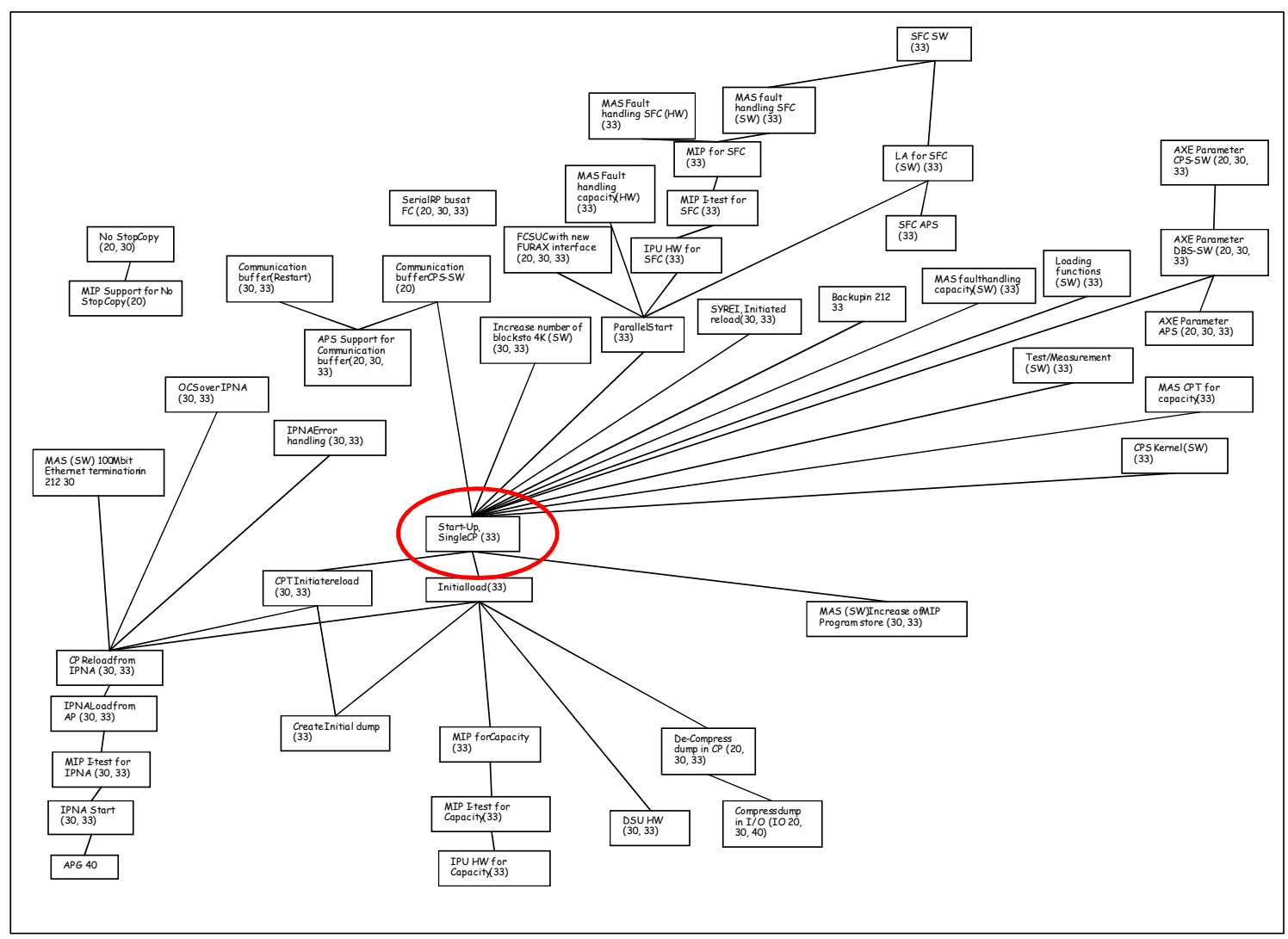

Figure 12: A system anatomy of a telecom processor

The boxes should be read as capabilities needed in the system. The dependencies (lines) proceed from the bottom to the top of the anatomy. If a certain capability fails in the dependency chain, (for example, the encircled "Start-Up Single CP" in the middle of the figure), the whole system will fail.

The anatomy can be interpreted as a conceptualization of the object in the activity of developing the telecom processor - a contemporary mammoth. As such, the anatomy is a means for coordinating actions, since it provides an easy to understand view of the target. In order to become useful, the anatomy must be jointly enacted by the actors the mammoth must come out of the fog, so to speak.

With the anatomy at hand, the capabilities to be developed are grouped into work packages. These packages are realized and verified by development units, which can be apprehended as activity domains. This is illustrated in Figure 13: 


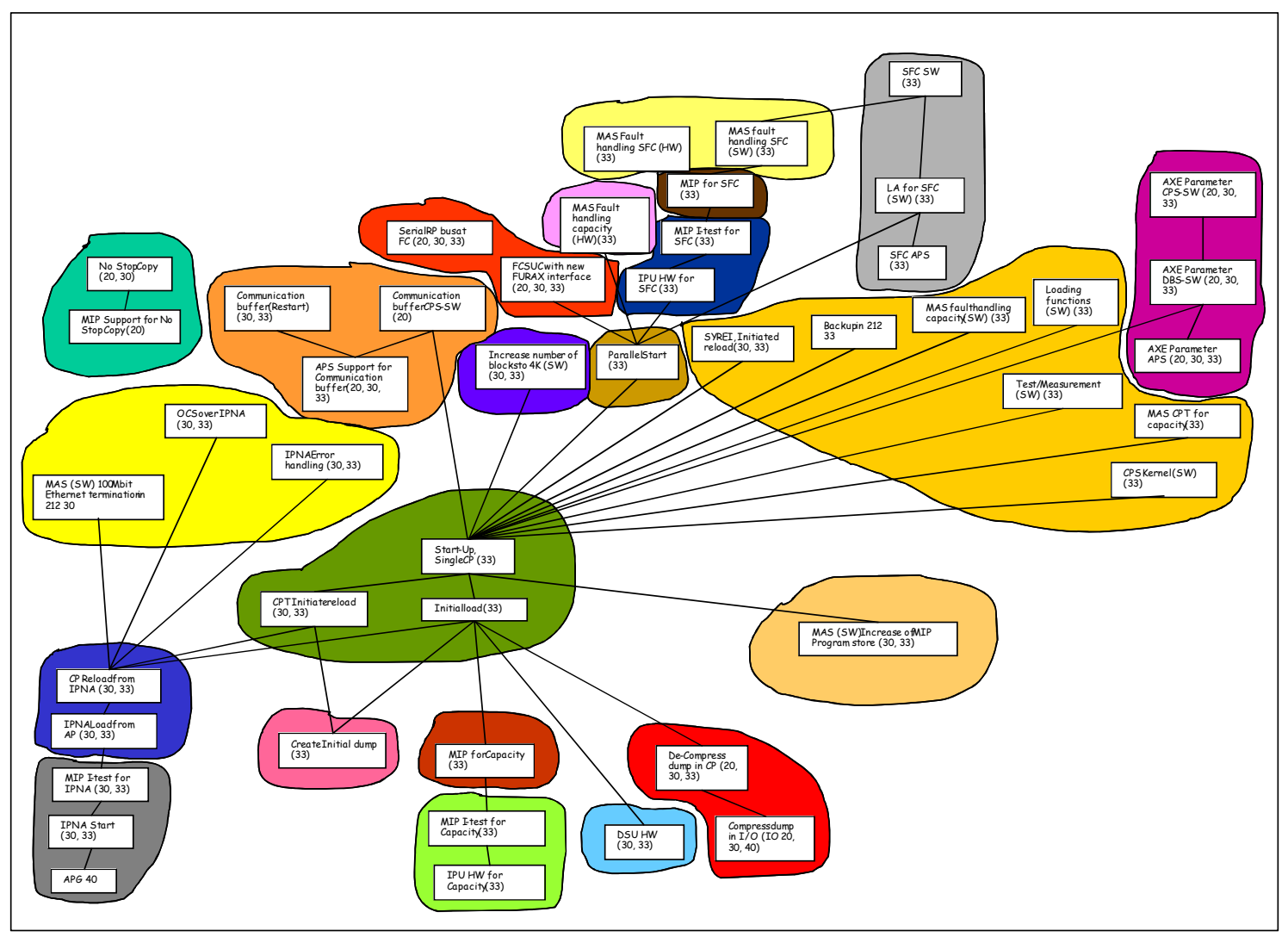

Figure 13: Activity domains developing specific capabilities in the processor.

Since the work packages are based on the anatomy, the dependencies between capabilities also define dependencies between activity domains. This makes it is easy to frame responsibilities. If some work package is delayed, all dependent packages will also be delayed.

For each work package, traditional time and resource plans are made as well. In Figure 14 , such a plan for the processor is shown. It can be seen that this plan is a 'tilted' variant of Figure 13 in which the temporal aspects are emphasized. 


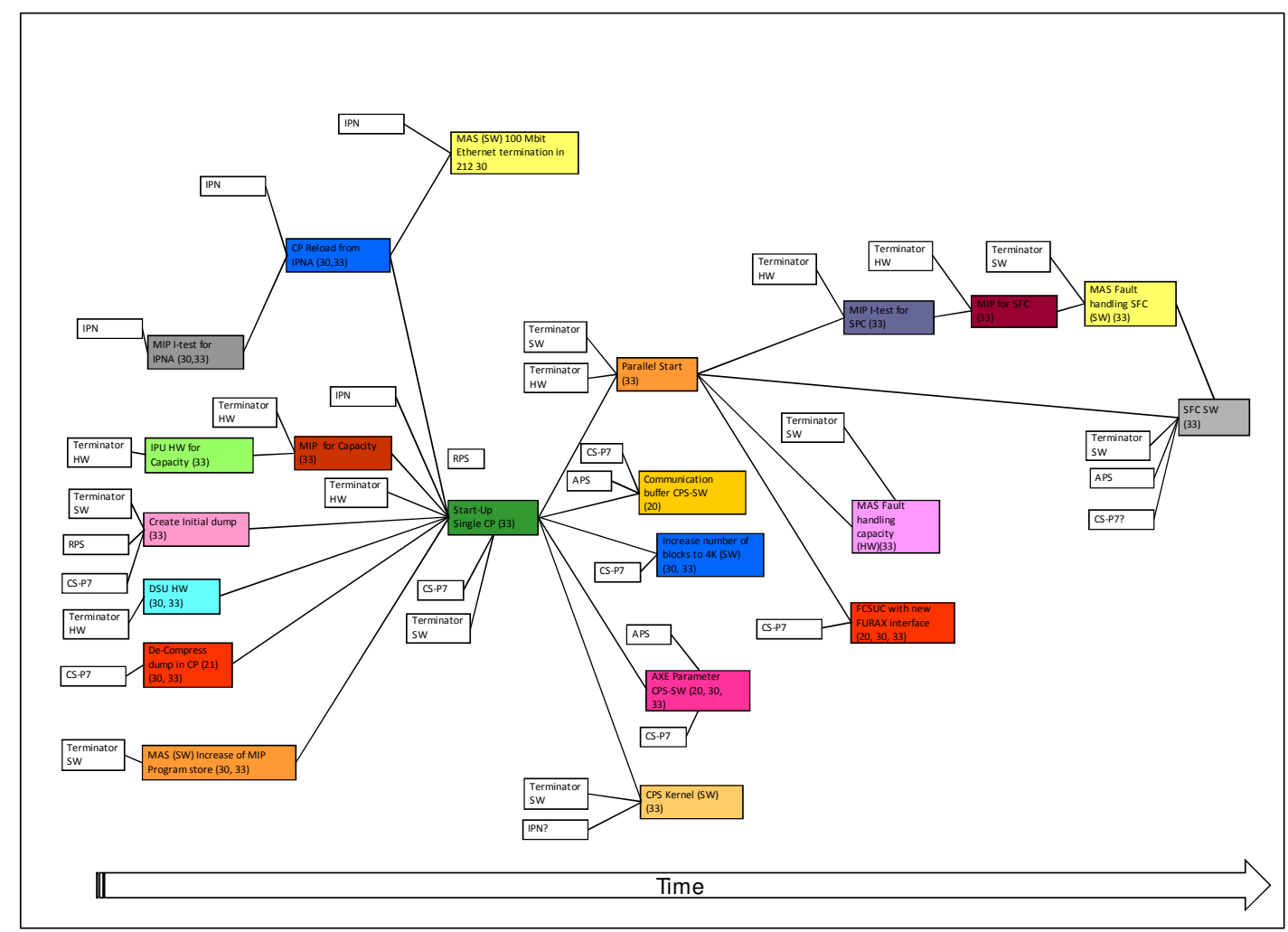

Figure 14: Emphasizing the temporalization modality.

When examined closer it appears that each separate image appears to be aligned with a dominant activity modality. The system anatomy in Figure 12 has a spatial structure since only static dependencies between capabilities in the system are shown. Figure 13 shows the dependencies between activity domains. Hence, the transition modality is in focus since this modality brings forward the coordination between domains. In Figure 14, temporalization is emphasized. Moreover, all modalities are related through the system anatomy.

The anatomy-based way of working has been proven exceptionally successful for coordinating extremely complex development projects at Ericsson. One possible explanation for this is that the approach is closely aligned with the modalities, and thus easier for us to comprehend and make use of in coordinating our actions.

\section{Information Systems}

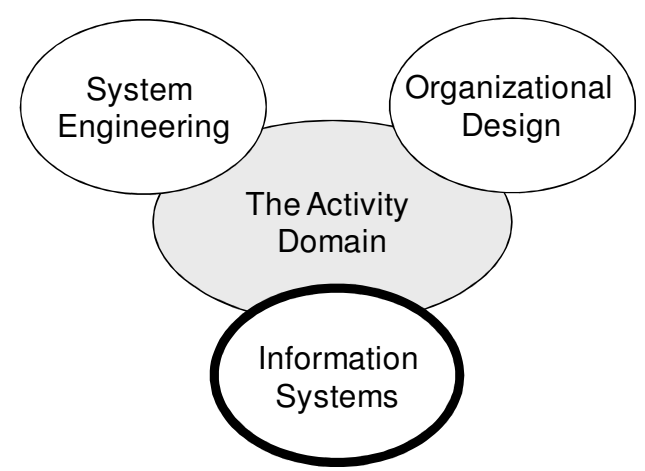

Figure 15: Focus on Information Systems 
The IS discipline has gone through several development phases. Early IS development methods concentrated on the technical aspect of the IS (Iivari \& Lyytinen, 1998). A clear separation was made between users and designers. However, largely influenced by Scandinavian researchers, the use context of the IS became more pronounced in design approaches such as the socio-technical, the trade-unionist, and the language action ones (ibid.). However, in all these approaches, the IS is still the target of the development.

With ADT the target is no longer only the IS, but the entire activity domain in which the IS is relevant. Thus, along with the IS also mediating artifacts in all activity modalities are constructed, such as the information model in Figure 8, the process model in Figure 9 , etc. In addition, a common understanding about the activity domain must be enacted. This means that all actors are contributing to the IS development, some more, some less. The basic mode of construction is an ongoing interaction between reflection and action as suggested by, for example, Truex, Baskerville \& Klein (1999).

In the ADT perspective, ISs are conceptualized as mediational means that manifests coordinative capabilities in all activity modalities. For example, in Figure 16 below, a screen shot is shown from an IS where the information model in Figure 8 has been implemented.

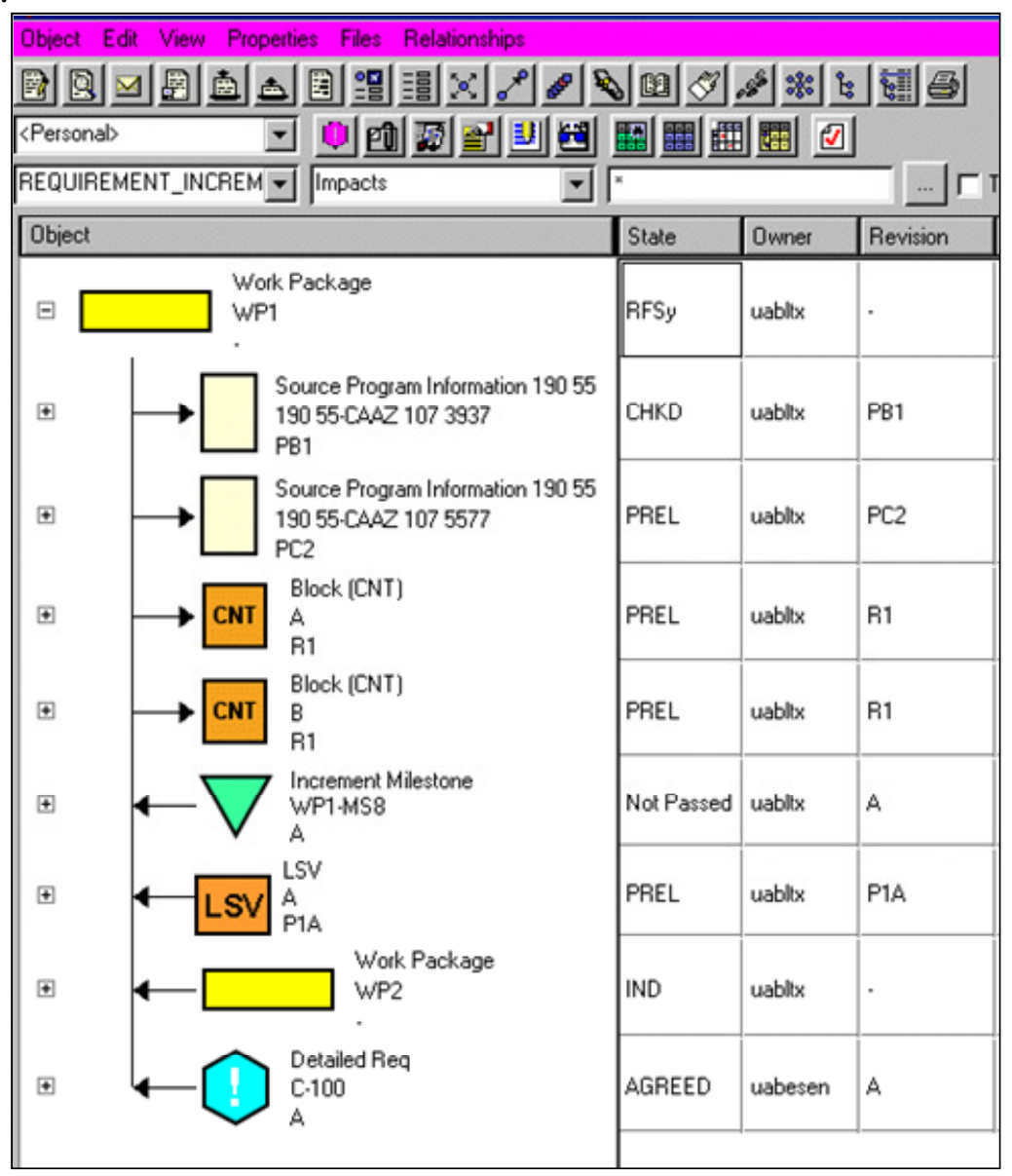

Figure 16: A screen shot from an IS

The manifestation of the activity models can be seen as follows. Contextualization is evident from the fact that the information shown is based on the information model as in Figure 8. Only such items that are relevant in the domain are visible in the IS. Spatialization is shown, among other things, in the relationships between items as 
indicated by the arrows. Temporalization can be noticed from the states of the items, since actions change the states. Stabilization is evident in the Ericsson specific way of naming items. Transition is not visible in the image, since it shows only the context of one domain. However, when the information is passed on to other ISs, transitional means such as IS interfaces are needed to transfer the information.

\section{BRINGING IT ALL TOGETHER}

In this section I will indicate how the understanding of the activity domain as the nexus of the organization may provide a unifying view of OD, SE, and IS.

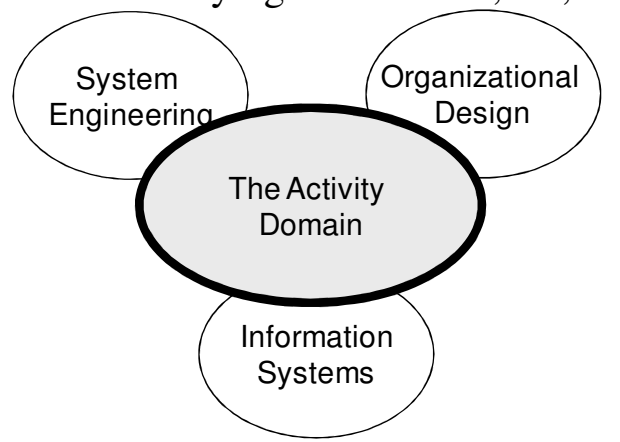

Figure 17: The unifying / integrating ADT perspective

The first step is to realize that the activity domains can be arranged in a dependency order - an organizational anatomy - in line with the system anatomy described earlier. Each domain provides an organizational capability that may depend on other capabilities provided by other domains or ESs. ES capabilities will be more or less relevant in different domains depending on the workobject and motive of the domain. For example, in a domain like financing, an ERP system is probably quite relevant in contrast to software development domain, in which a PLM system might be more relevant. In addition, other necessary capabilities, such as those provided by the IS/IT infrastructure, can be inserted in the anatomy. In Figure 18, one example of such an organizational anatomy from Ericsson is shown: 


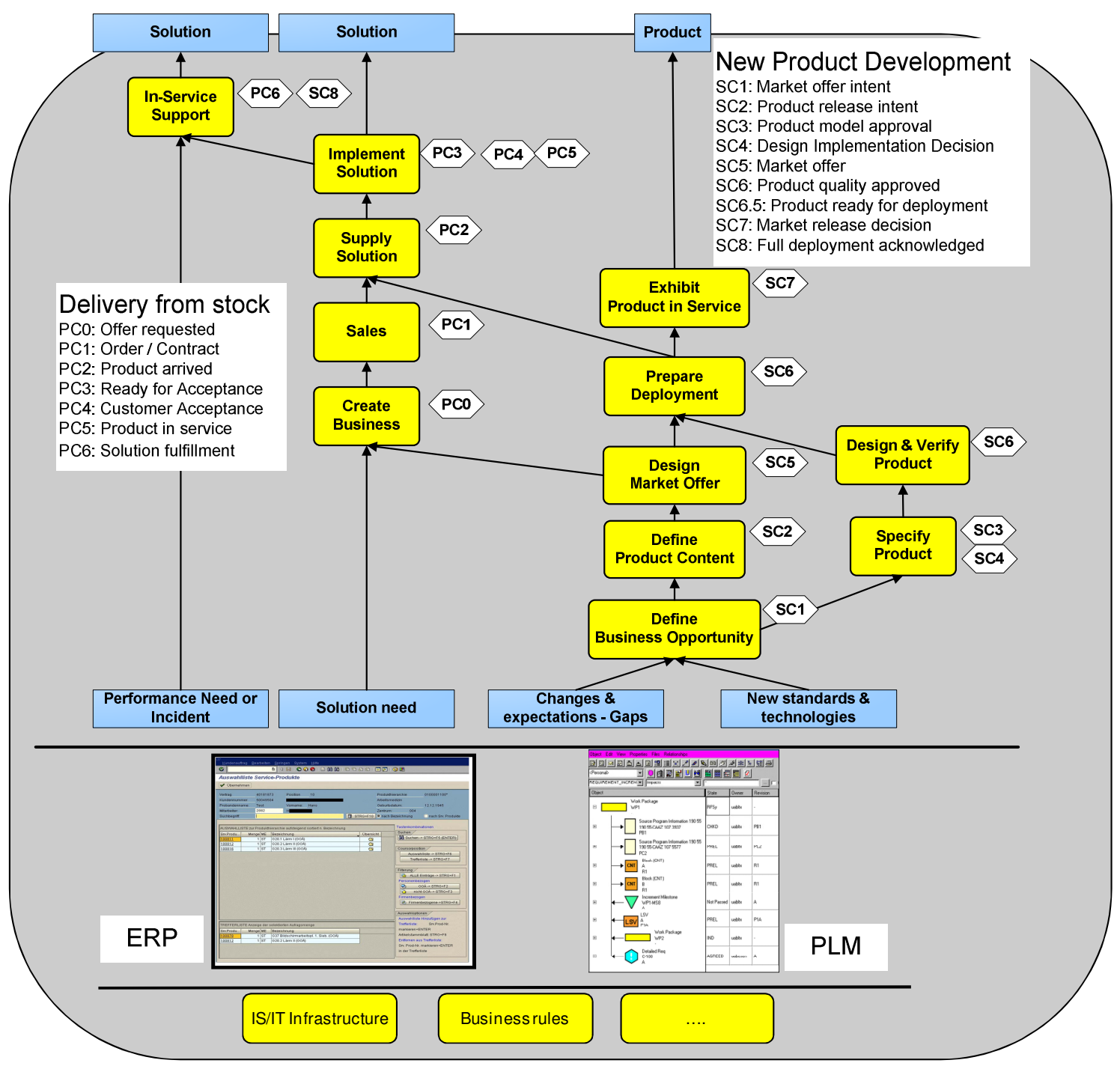

Figure 18: An organizational anatomy

It might be argued that the anatomy is nothing but a rearrangement of the business process in Figure 9. However, from an ontological perspective, there is a profound difference. In contemporary organizational discourse, the nexus of the organization is the process, meaning that all other organizational constructs are subordinate. In the ADT perspective however, a process is a manifestation of temporalization, which means that it is but one of the modalities.

By apprehending the activity domain as the nexus of the organization, it is possible to use the organizational anatomy as a means for analytical and constructive organizational interventions as follows (for a full account, see Taxén, 2008; 2009b).

\section{Implementing a business strategy}

A business strategy is a plan that directs a business to achieve its goal in the most efficient way. The strategy determines "the basic long-term goals and objectives of an enterprise and the adoption of courses of action and the allocation of resources necessary for carrying out these goals" (Chandler, 1966, p. 16). This connects nicely with the organizational anatomy, which illustrates useful capabilities in the context of the organization, i.e. resources. 
From a strategic point of view, one task is to decide how the domains contribute to the fulfillment of the strategic intentions of the organization. This task may be informed by the organizational anatomy. For example, if many domains depend on an outsourced domain, this is easily recognized in the anatomy. Such a dependency may expose the organization to a high a risk, especially if the outsourced domain cannot be easily replaced.

\section{Aligning business strategies and knowledge strategies}

Knowledge strategies are concerned with the linking of "knowledge-oriented processes, technologies, and organizational forms to business strategy" (Zack, 1999, p. 126). The term "knowledge strategy" appeared in response to the observation that knowledge management initiatives seldom were correlated with business strategy initiatives (Callahan, 2002). Knowledge strategies can therefore be seen as an aspect of business strategy that takes into account the intellectual resources and capabilities of the organization (ibid.).

With the anatomy at hand, targets for knowledge strategies can be identified and capability gaps remedied. Since capabilities are considered as jointly achieved by humans and means, gaps can either be related to humans or means. The first case can be characterized as "we have access to this magnificent tool in our domain, but we cannot use it". The second case can be characterized as "We know how to use this magnificent tool we urgently need here, but unfortunately we do not have access to that tool". Regardless of whether gaps appear in humans or means, it is important not to detach these from each other.

\section{Alignment of business strategies and IT capabilities}

Since the organizational anatomy includes both activity domains and IT systems, the anatomy provides a means to align IT with the strategic intents of the organization. In order to achieve this, an anatomy of the IT system itself needs to be developed. In Figure 19 an example of an ES anatomy is given: 


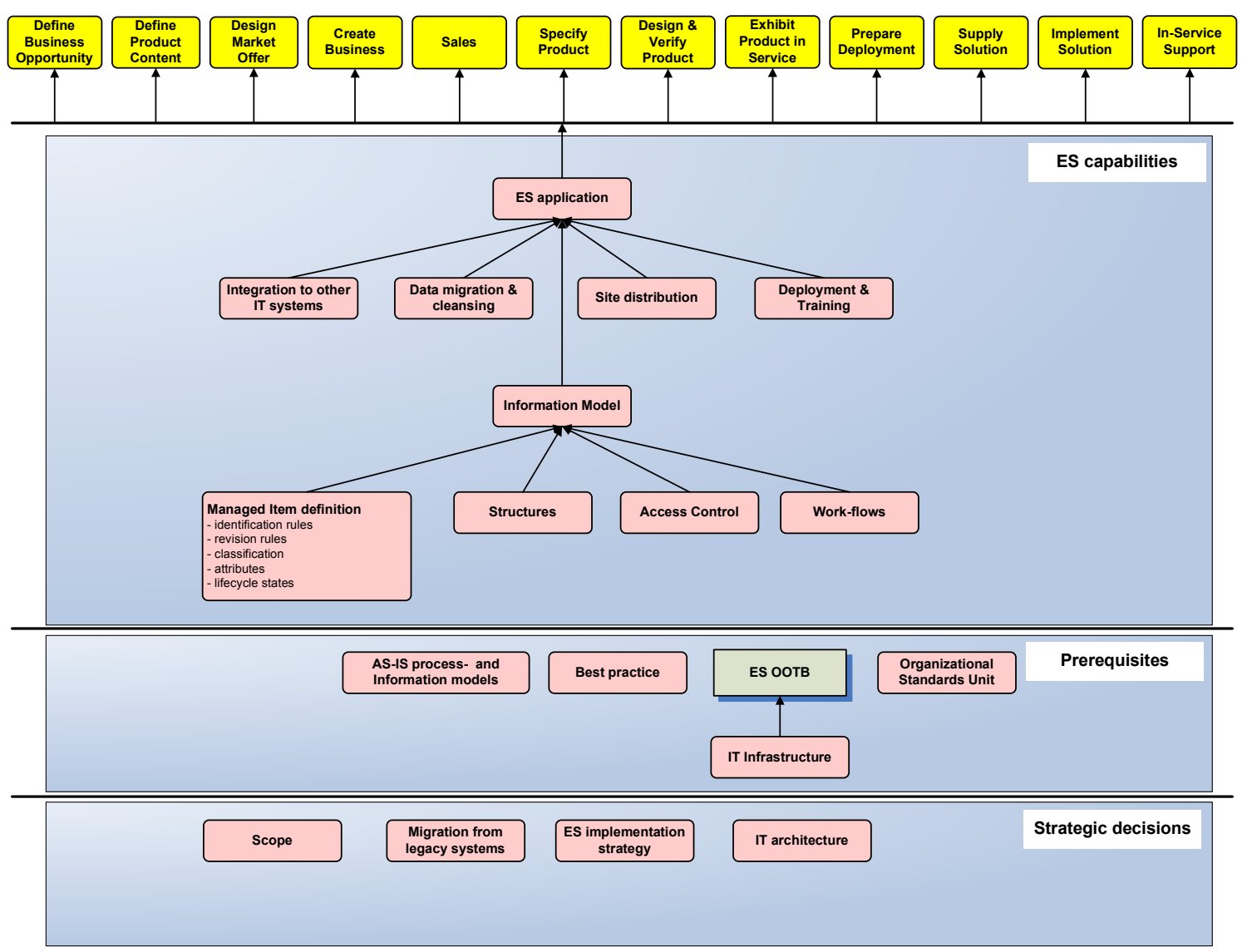

Figure 19: An anatomy for an Enterprise System

Basically, three groups of capabilities can be identified: strategic decisions, prerequisites and ES capabilities. When focusing on the ES anatomy, the dependencies between the activity domains are not important, which is the reason why the domains are lined up at the top, indicating that these are the 'clients' of the ES capabilities. The only thing that matters is if the ES is relevant in the context of the domain or not. As with other system anatomies, the ES anatomy it is an excellent means for planning and monitoring an ES implementation project.

\section{DISCUSSION AND CONCLUSIONS}

Which are the implications of the ADT approach? A key insight is that the activity modalities provide a cohesive way of making inquiries into both the human mind and social reality. If indeed the modalities represent innate predispositions for acting in the world, cognitive science, neuropsychology, neurophysiology, linguistics, and other human-oriented disciplines should be able to trace the modalities in their respective area of investigation. A first attempt to do so is found in Taxén (n.d.). Conversely, as has been demonstrated by the examples from Ericsson, manifestations of the modalities can be investigated in various areas of investigations such as OD, SE and IS.

The main impact for OD is the conceptualization of organizations as confederations of activity domains. By placing the activity domain "in the centre of the world", alternative ways of organizational inquiry are opened up. To give but one example, Grant has formulated the essence of organizational capability as "knowledge integration":

If the strategically most important resource of the firm is knowledge, and if knowledge resides in 
specialized form among individual organizational members, then the essence of organizational capability is the integration of individuals' specialized knowledge. (Grant, 1996b, p. 375)

Grant also points out that there is an inherent conflict in knowledge integration:

[Knowledge integration] depends upon the extent of commonality in [...] specialized knowledge. There is something of a paradox in this. The benefit of knowledge integration is in meshing the different specialized knowledge of individuals - if two people have identical knowledge there is no gain from integration - yet, if the individuals have entirely separate knowledge bases, then integration cannot occur beyond the most primitive level. (Grant, 1996., p. 116)

Conceptualizing knowledge integration as something that goes on directly between the individual and the organization is most certainly a dead end from an operational point of view. As shown above, individuals work on many different workobjects that contribute to the final organizational outcome. Moreover, Virkkunen \& Kuutti emphasize the importance of relating all knowledge in organizations to workobjects:

Organizations are not basically knowledge systems, but systems that produce something of value to the society. [...] Only when the knowledge-creation process is set into the context of an organization's activities, does the understanding of the knowledge processes help us understand organizational learning. (Virkkunen \& Kuutti, 2000, p. 297)

By regarding the activity domain as an intermediate construct between the individual and the organization, it becomes possible to identify what kind of knowledge is needed in relation to each particular workobject. The knowledge integration problem may then be formulated in terms of coordinating the domains, and finding an optimal balance between internal/external aspects of each domain.

The recursive nature of the activity domain implies that the notion of 'levels' is given a specific interpretation in organizational discourse. Rather than investigating groups, teams, projects, business units, organizations, networks of organizations, etc., as separate units of analysis, these are all considered as activity domains with the same fundamental structure. 'Level' connotes a sense of hierarchy which is not present in ADT. The activity domain provides a common ground for analysis that cuts through all 'levels'; a ground from which the specifics of each 'level' can be separately investigated. Rather than focusing on the thorny issue of "crossing" levels, i.e., what goes on between levels, investigation efforts are refocused to how transition between domains take place.

Regarding the issue of 'local' versus 'global', this must be seen in relation to the confederation of activity domains. 'Local' refers to the internal of each domain and 'global' to the surrounding, external coordinating domain; indicating that these concepts need to be interpreted relative each particular activity domain.

Concerning SE, tentative evidences from the anatomy-based approach indicate that SE methods would benefit from being aligned with the activity modalities. Moreover, there is a need to include interpretation and meaning construction as inherent aspects of SE work. In addition, the workobject should be represented in such a way that dependencies between capabilities are emphasized.

The main consequence for the IS area is that ESs like ERP and PLM systems are regarded as means mediating coordinative capabilities. In practice, this means that spatial, temporal, stabilizing, and transitional elements, as well how these relate to each other, need to be managed in ESs. Depending on the context of each impacted domain, 
the ES is differently conceived. Some domains may use the full capabilities of the ES, while other domains may just be a provider of information to the ES.

With the activity domain as the nexus of the organization, coordination can be given an interpretation as the management of dependencies between capabilities of activity domains. This enables the conceptualization of the organization as an organizational anatomy; that is, a visual image - an "organizational mammoth" if you like - of the organization as a workobject. Given the favorable experiences from using the anatomy concept in systems development, it might be hoped that the organizational anatomy provides a similar, powerful means to analyze and intervene in organizations.

Finally, some words concerning the limitations of the ADT approach. It must be remembered that ADT is concerned only with the coordination of actions. Other highly relevant aspects of organizations, such as power, financing, team building, emotions, leadership, and much more, are outside the scope of the theory. However, with the activity domain as the nexus of the organization, all these left-out aspects can be related to a common ground, which hopefully will strengthen the analysis.

In conclusion, according to Engeström, "coherent new theoretical frameworks that attempt to overcome the aged dichotomies between micro- and macro-, mental and material, quantitative and qualitative, observation and intervention, are few and far between" (Engeström. 2000, p. 961). In this contribution I have suggested the Activity Domain Theory as one such possible framework. Whether this is a viable approach remains to be demonstrated. However, there are some features of ADT that distinguishes the framework from similar practice-oriented approaches reported in the literature ${ }^{3}$ :

- The ADT was born in the practice of coordinating extremely complex telecommunication projects. Thus, the theory is firmly grounded in practical experiences, and only subsequently grounded in other theories like Activity Theory. This is in contrast to most other theories in the IS area. In general, such theories are appropriated and adapted from theories originated in other areas. One example is that Structuration Theory (Giddens, 1984), which has been extensively used to in IS research (Jones \& Karsten, 2008).

- Due to its roots in practice, ADT has from the outset included operational, constructive aspects in addition to analytical aspects. Most other frameworks originating in research is mainly focused on analyzing practice rather than influencing it.

- In the IS area, ES focus has almost exclusively been on ERP systems. In contrast, the experiences contributing to the development of ADT come mainly from working with PLM systems.

Perhaps the most salient feature that demarcates ADT from other theories is that ADT is ultimately grounded in innate predispositions for coordinating actions. The activity modalities may be regarded as an extension of Kant's a priori categories of space and

\footnotetext{
${ }^{3}$ A thorough evaluation of such approaches in relation to ADT is given in Taxén (2009).
} 
time (Kant, 1924). As such, they represent an elaboration of basic human features into the social arena, thus providing a unifying framework for coordinating actions that spans aspect ranging from the individual psyche to the construction of organizations.

\section{REFERENCES}

Akkermans, H., van Helden, K. (2002). Vicious and virtuous cycles in ERP implementation: a case study of interrelations between critical success factors. European Journal of Information Systems, 11, 35-46.

Al-Mashari, M., \& Zairi, M. (1999). BPR implementation process: an analysis of key success and failure factors. Business Process Management Journal, 5(1), 87 112.

Arsanjani, A., Zhang, L. J., Ellis, M., Allam, A., \& Channabasavaiah, K. (2007). S3: A Service-Oriented Reference Architecture. IT Professional, 9(3), 10-17.

Bechky, B. A. (2003). Sharing meaning across occupational communities: The transformation of understanding on a production floor. Organization Science 14(3), 312-330.

Bechky, B. A. (2006). Gaffers, gofers, and grips: Role-based coordination in temporary organizations. Organization Science 17(1), 3-21.

Bryant, W. C., \& Gay, S. H. (1883). A Popular History of the United States. Vol. I, New York: Charles Scribner's Sons.

Bødker, S., \& Bøgh Andersen, P. (2005). Complex Mediation. Human-Computer Interaction, 20, 353-402.

Callahan, S.D. (2002). Crafting a knowledge strategy. In ACT Knowledge Management Forum (ActKM) Conference, Canberra (ActKM). Retrieved Jan 2, 2009, from http://www.anecdote.com.au/papers/CallahanCraftingKnowledgeStrategy.pdf

Chandler, A. (1966). Strategy and Structure. Garden City, N.Y.: Doubleday \& Company.

Earl, M. J. (1996). An Organizational Approach to IS Strategy Making. in M. J. Earl (Ed.), Information Management - The Organizational Dimension (pp. 136-170). Oxford: Oxford University Press.

Engeström, Y. (2000). Activity theory as a framework for analyzing and redesigning work. Ergonomics, 43(7), 960-974.

Giddens A (1984) The Constitution of Society, Cambridge: Polity Press.

Grant, R. M. (1996). Toward a Knowledge-Based Theory of the Firm. Strategic Management Journal, 17, Winter Special Issue, 109-122.

Grant, R. M. (1996b). Prospering in Dynamically-competitive Environments: Organizational Capability as Knowledge Integration. Organization Science, 7(4), 375-387.

Iivari, J., \& Lyytinen, K. (1998). Research on Information Systems Development in Scandinavia - Unity in Plurality. Scandinavian Journal of Information Systems, 10 (1\&2), 135-186. 
Israel, J. (1979). The language of dialectics and the dialectics of language. New York: Humanities Press.

Jones, M., \& Karsten, H. (2008). Giddens's Structuration Theory and Information Systems Research. MIS Quarterly 32(1), 127-157

Kant, I. (1924). Critique of pure reason. London: Bell

Kaptelinin, V., \& Nardi, B. (2006). Acting with Technology - Activity Theory and Interaction Design. Cambridge, MA: The MIT Press.

Kim, J., Lee, Z., \& Gosain, S. (2005). Impediments to successful ERP implementation process. Business Process Management Journal, 11 (2), 158-170.

Klein, H., \& Myers, M. D. (1999). A Set of Principles for Conducting and Evaluating Interpretive Field Studies in Information Systems. MIS-Quarterly 23(1), 76-93.

Lawrence, P., \& Lorsch, W. (1967). Differentiation and Integration in Complex Organizations. Administrative Science Quarterly, 12(1), 1-47.

Leont'ev, A. N. (1981). Problems in the development of the mind. Moscow: Progress Publ.

McCubbrey, D.J. (2003). The IS Core - IV: IS Research: A Third Way. Communications of the AIS, 12(34), 553-556.

Miettinen, R., Samra-Fredericks, D., \& Yanow, D. (2009). Re-Turn to Practice: An Introductory Essay. Organization Studies, 30(12), 1309-1327.

Nicolini, D. (2009). Zooming In and Out: Studying Practices by Switching Theoretical Lenses and Trailing Connections. Organization Studies, 30(12), 1391-1418.

Nicolini, D. (2010). Practice as the Site of Knowing: Insights from the Field of Telemedicine. Organization Science, Articles in Advance, 1-19.

Orlikowski, W. (2000). Using Technology and Constituting Structures: A Practice Lens for Studying Technology in Organizations. Organization Science, 11(4), 404-428.

Orlikowski, W. J., and Scott, S. V. (2008). Sociomateriality: Challenging the Separation of Technology, Work and Organization. The Academy of Management Annals 2(1), 433-474.

Parnas, D.L. (1995). On ICSE's 'most influential' papers. ACM SIGSOFT, 20(3), 29-33.

Simpson, B. (2009. Pragmatism, Mead and the Practice Turn. Organisation Studies, 30(12), 1329-1347.

Schmidt, K. (1990). Analysis of Cooperative Work. A Conceptual Framework. Ris $\varnothing$ National Laboratory, DK-4000 Roskilde, Denmark, [Risø-M-2890].

Schmidt, K. \& L. Bannon, (1992). Taking CSCW Seriously: Supporting articulation work. Computer Supported Cooperative Work, 1(1-2), 7-40. Retrieved April 4, 2008, from http://citeseer.ist.psu.edu/schmidt92taking.html

Taxén, L. (2008). The Activity Domain Theory - Informing the Alignment of Business and Knowledge Strategies. In E. Abou-Zeid (Ed.), Knowledge Management and Business Strategies: Theoretical Frameworks and Empirical Research (pp. 253280), Hershey PA: Information Science Reference, (IGI Global). ISBN: 978-159904-486-6 
Taxén, L. (2009). Using Activity Domain Theory for Managing Complex Systems. Information Science Reference. Hershey PA: Information Science Reference (IGI Global). ISBN: 978-1-60566-192-6.

Taxén, L. (2009b). A Practical Approach for Aligning Business and Knowledge Strategies. In M. Russ (Ed.), Knowledge Management Strategies for Business Development (pp. 277-308), Hershey PA: Business Science Reference (IGI Global). ISBN: 978-1-60566-348-7.

Taxén, L. (n.d.). Modeling the Intellect from a Coordination Perspective. In B. Igelnik (Ed.), Computational Modeling and Simulation of Intellect: Current State and Future Perspectives. Hershey PA: IGI Global

Taxén, L. (Ed.) (n.d.2). The System Anatomy - Enabling Agile Project Management. Lund: Studentlitteratur.

Truex, D., P., Baskerville, R., Klein, H. (1999). Growing Systems in Emergent Organizations. Communication of the ACM, 42(8), 117-123.

Weick, K. E. (1988). Enacted sensemaking in crisis situations. Journal of Management Studies, 25(4), 305-317.

Wertsch, J. V. (1991). Voices of the mind: a sociocultural approach to mediated action. Cambridge, Mass.: Harvard University Press.

Wiley, N. (1988). The Micro-Macro Problem in Social Theory. Sociological Theory, $6(2), 254-261$.

Wikipedia (2010) Retrieved Jan 24, 2011, from http://en.wikipedia.org/wiki/Systems_engineering

Wikipedia (2010b) Retrieved Jan 24, 2011, from http://en.wikipedia.org/wiki/Product_lifecycle_management

Virkkunen, J., \& Kuutti, K .(2000). Understanding organizational learning by focusing on "activity systems". Accounting, Management and Information Technologies, 10 (4), 291-319.

Yanow, D. (2006). Talking about Practices: On Julian Orr's Talking About Machines. Organization Studies, 27(12), 1743-1756.

Zack, M. (1999). Developing a Knowledge Strategy. California Management Review, 41(3), 125-145. 